\title{
Amine Modification of Digested Peptide at C-Terminal End during Protein Digestion by Protease
}

\author{
Toshiyuki Ito, ${ }^{a}$ Yoshiaki Sugita, ${ }^{b}$ Koichi Takao, ${ }^{b}$ Yoshihiko Ikeguchi, ${ }^{a}$ and Akira ShirahatA $*, a, b$ \\ ${ }^{a}$ Department of Biochemistry, Faculty of Pharmaceutical Sciences, Josai University; and ${ }^{b}$ Department of Human Nutrition \\ and Clinical Dietetics, Faculty of Pharmaceutical Sciences, Josai University; 1-1 Keyakidai, Sakado, Saitama 350-0295, \\ Japan. Received May 22, 2007; accepted August 5, 2007; published online August 7, 2007
}

\begin{abstract}
We recently reported that $C$-terminal polyamine modification occurs when proteins are digested with trypsin in the presence of polyamine [Biochem. Biophys. Res. Commun., 356, 159-162 (2007)]. In the present study, the characteristics of this $C$-terminal modification in the presence of protease and amine were investigated. When hemoglobin (HB) was digested with trypsin in the presence of $\mathrm{N}$-(2-pyridyl)-1,4-diaminobutane (Py4), formation of the modified peptide was dependent on time and on $\mathrm{HB}$ or Py4 concentration. When synthetic peptide was treated with trypsin in the presence of Py4, ca. $0.1 \%$ of the peptide was modified with Py4. When HB or cytochrome $C$ was treated with a range of serine proteases in the presence of various amines (Py4, $N$-(2-pyridyl)1,3-diaminopropane, tranexamic acid, isonicotinic acid hydrazide and ampicillin), the modified peptide was detected in all cases tested, thus suggesting that amine modification widely accompanies digestion by proteases.
\end{abstract}

Key words amine; protease; modification; C-terminus; amino group; digestion

Transglutaminase (TGase) is a typical enzyme that catalyzes the post-translational cross-linking of proteins by acyl transfer in mammalian cells. TGases use a cysteine proteaselike catalytic mechanism to release ammonia from proteinbound glutamine by forming a $\gamma$-glutamyl-enzyme thioester intermediate, which subsequently transfers the $\gamma$-glutamyl moiety to another amine (transamidation), an aliphatic alcohol (esterification), or water (glutamine hydrolysis; deamidation). ${ }^{1)}$ In vitro, numerous amines, diamines, polyamines, and alcohols are capable of interacting with the protein-acyl-enzyme intermediate. ${ }^{1)}$ Therefore, all enzymatic reactions via protein-acyl-enzyme intermediates have the potential for producing amine-modified peptides or proteins in enzymatic systems in the presence of amino compounds.

Serine proteases are known to form protein-acyl-enzyme intermediates. ${ }^{2)}$ These proteases hydrolyze proteins in two steps. The first step is the acylation of the serine residue, which results in the liberation of the $\mathrm{C}$-terminal peptide. The second step is hydrolysis of the acyl-enzyme intermediate, which results in elimination of the N-terminal peptide. We recently reported that $\mathrm{C}$-terminal polyamine modification of digested peptides occurs when hemoglobin (HB) is digested with trypsin in the presence of polyamine. ${ }^{3)}$ This suggests that removal of the C-terminal peptide in the hydrolysis reaction produces sufficient space in the vicinity of the proteinacyl-trypsin intermediate to allow an alkylamine with an unshared electron pair, such as polyamine, to attack the proteinacyl-enzyme intermediate instead of a hydroxyl ion. Such modification could occur widely with other amines including drugs having an amino group, as well as polyamines, during protease digestion. If biological amine- or drug-modified peptides were produced in the intestinal tract, this modification may be related to unknown nutrient-nutrient interactions or drug-nutrient interactions.

In the present study, in order to investigate the characteristics of amine modification, the production of modified peptides was examined using a model alkylamine, $N$-(2-pyridyl)1,4-diaminobutane (Py4), with intestinal proteases (trypsin, chymotrypsin and elastase) and synthetic peptides. Further- more, the possibility of in vitro production of peptides modified by a variety of alkylamines, including drugs, was evaluated.

\section{MATERIALS AND METHODS}

Materials Bovine HB, ampicillin (Amp), 1-octaneslufonic acid sodium salt and high performance liquid chromatography (HPLC) grade trifluoroacetic acid were obtained from Wako Pure Chemical Industries (Osaka, Japan); isonicotinic acid hydrazide (INH), tranexamic acid (TA) and 4bromobenzylamine (BrBA) hydrochloride were obtained from Tokyo Chemical Industry Co. (Tokyo, Japan); chymotrypsin (sequencing grade) was obtained from Roche (Mannheim, Germany); modified trypsin (sequencing grade) was obtained from Promega (Madison, WI, U.S.A.); 2-[4-(2hydroxyethyl)-1-piperazinyl]-ethanesulfonic acid (HEPES), elastase, horse cytochrome C (CytC), angiotensin II, bovine insulin $\beta$ chain and $\alpha$-cyano-4-hydroxycinnamic acid were obtained from SIGMA (St. Louis, MO, U.S.A.); synthetic peptides (SLIGKV-OH and SFLLRN-NH ${ }_{2}$ ) were obtained from Bachem (Bubendorf, Switzerland); and HPLC grade acetonitrile was purchased from KANTO KAGAKU (Tokyo, Japan).

$N$-(2-Pyridyl)-diaminoalkanes were synthesized in our laboratory.

For $N$-(2-pyridyl)-1,3-diaminopropane (Py3), a mixture of 2-bromopyridine $(5.0 \mathrm{ml}, 51.6 \mathrm{mmol})$ and 1,3-diaminopropane $(21 \mathrm{ml}, 258 \mathrm{mmol})$ were stirred under a nitrogen atmosphere at $130^{\circ} \mathrm{C}$ for $19 \mathrm{~h}$. Then, $4 \mathrm{~mol} / 1$ ammonia solution $(15 \mathrm{ml})$ was added to the mixture, and the product was extracted with chloroform $(6 \times 30 \mathrm{ml})$. The organic layer was dried $\left(\mathrm{MgSO}_{4}\right)$, and the solvent was evaporated. The oil residue was distilled under reduced pressure $\left(160-165^{\circ} \mathrm{C}\right.$, $12 \mathrm{mmHg})$ to give Py3. After adding ethanol $(10 \mathrm{ml})$ and concentrated hydrochloric acid $(6.2 \mathrm{ml})$, the solvent was evaporated to give Py3 hydrochloride. The white crystals obtained were recrystallized with ethanol. White crystals, $47 \%$ yield; ${ }^{1} \mathrm{H}-\mathrm{NMR}\left(\mathrm{D}_{2} \mathrm{O}\right) \delta 1.90-1.97(2 \mathrm{H}, \mathrm{m}, \mathrm{H}-2), 2.99(2 \mathrm{H}$, 
$\mathrm{t}, J=7.8 \mathrm{~Hz}, \mathrm{H}-3), 3.34(2 \mathrm{H}, \mathrm{t}, J=6.8 \mathrm{~Hz}, \mathrm{H}-1), 6.89(1 \mathrm{H}, \mathrm{d}$, $J=9.1 \mathrm{~Hz}, \mathrm{PyH}-3), 6.76(1 \mathrm{H}$, ddd, $J=7.0,6.4,0.9 \mathrm{~Hz}, \mathrm{PyH}-$ 5), $7.65(1 \mathrm{H}, \mathrm{dd}, J=6.4,1.5 \mathrm{~Hz}, \mathrm{PyH}-6), 7.76(1 \mathrm{H}$, ddd, $J=9.1,7.0,1.5 \mathrm{~Hz}, \mathrm{PyH}-4$ ). FAB-MS m/z: 152 (Calcd for $\mathrm{C}_{8} \mathrm{H}_{14} \mathrm{~N}_{3}$ : 152). Anal. Calcd for $\mathrm{C}_{8} \mathrm{H}_{15} \mathrm{~N}_{3} \mathrm{Cl}_{2}: \mathrm{C}, 42.87 ; \mathrm{H}$, $6.75 ; \mathrm{N}, 18.75$. Found: C, 42.87; H, 6.82; N, 18.76 .

For $N$-(2-pyridyl)-1,4-diaminobutane (Py4), a mixture of 2-bromopyridine $(20 \mathrm{ml}, 0.21 \mathrm{~mol})$ and 1,4-diaminobutane $(106 \mathrm{ml}, 1.06 \mathrm{~mol})$ were stirred under a nitrogen atmosphere at $120^{\circ} \mathrm{C}$ for $10 \mathrm{~h}$. Then, $4 \mathrm{~mol} / 1$ ammonia solution $(200 \mathrm{ml})$ was added to the mixture and the product was extracted with chloroform $(4 \times 600 \mathrm{ml})$. The organic layer was dried $\left(\mathrm{MgSO}_{4}\right)$, and the solvent was evaporated. The oil residue was purified on a chromatography column (silica gel) using a mixture of chloroform-methanol $(10: 1)$ to give Py4. After adding ethanol $(20 \mathrm{ml})$ and concentrated hydrochloric acid $(26.7 \mathrm{ml})$, the solvent was evaporated to give Py4 hydrochloride. The white crystals obtained were recrystallized with ethanol. White crystals, 59\% yield; ${ }^{1} \mathrm{H}-\mathrm{NMR}\left(\mathrm{D}_{2} \mathrm{O}\right) \delta 1.56$ 1.68 (4H, m, H-2, H-3), 2.90 (2H, t, $J=7.3 \mathrm{~Hz}, \mathrm{H}-4), 3.26$ $(2 \mathrm{H}, \mathrm{t}, J=6.4 \mathrm{~Hz}, \mathrm{H}-1), 6.71(1 \mathrm{H}, \mathrm{ddd}, J=7.0,6.4,0.9 \mathrm{~Hz}$, PyH-5), 6.86 (1H, d, $J=9.1 \mathrm{~Hz}, \mathrm{PyH}-3), 7.61$ (1H, dd, $J=6.4$, $1.5 \mathrm{~Hz}, \mathrm{PyH}-6), 7.72$ (1H, ddd, $J=9.1,7.0,1.5 \mathrm{~Hz}, \mathrm{PyH}-4)$. FAB-MS m/z: 166 (Calcd for $\mathrm{C}_{9} \mathrm{H}_{16} \mathrm{~N}_{3}$ : 166). Anal. Calcd for $\mathrm{C}_{9} \mathrm{H}_{17} \mathrm{~N}_{3} \mathrm{Cl}_{2}$ : C, 45.39; H, 7.19; N, 17.64. Found: C, 45.23; H, 7.28; N, 17.54 .

Enzymatic Digestion of Proteins or Peptides HB or $\mathrm{CytC}$ digestion with protease (trypsin, chymotrypsin or elastase) was performed at a concentration of $1.0 \mathrm{mg} / \mathrm{ml}$ in $100 \mathrm{~mm}$ HEPES buffer ( $\mathrm{pH}$ 7.5) in the presence or absence of $50 \mathrm{~mm}$ alkylamines. Digestion of synthetic peptides (SLIGKV-OH or SFLLRN-NH ${ }_{2}$ ) was performed at a concentration of $12.5 \mathrm{~mm}$. The mass ratio of $\mathrm{HB}, \mathrm{CytC}$, SLIGKV$\mathrm{OH}$ or SFLLRN-NH $\mathrm{N}_{2}$ to proteases was $1: 20,1: 20,1: 60$ or $1: 75$, respectively. Reaction mixtures were incubated at $37^{\circ} \mathrm{C}$ for $16 \mathrm{~h}$. Some reactions were performed in a mixture of $100 \mathrm{~mm}$ HEPES buffer (pH 7.5) and methanol.

Fractionation of Enzyme Digestion Products Protease digestion products were fractionated by HPLC on a packed $\mathrm{C}_{18}$ column (TOSOH ODS $120 \mathrm{~T}, 4.6 \times 250 \mathrm{~mm}$ ). Flow rate was $1.0 \mathrm{ml} / \mathrm{min}$ and column temperature was $35^{\circ} \mathrm{C}$. UV absorption was monitored at $220 \mathrm{~nm}$. Fluorescence was monitored at Ex $310 \mathrm{~nm}$ and Em $390 \mathrm{~nm}$.

For fractionation of digested $\mathrm{HB}$ or $\mathrm{CytC}$, solvents for HPLC were: A, 5\% acetonitrile containing $0.1 \%$ trifluoroacetic acid; B, $80 \%$ acetonitrile containing $0.1 \%$ trifluoroacetic acid. The column was equilibrated with $100 \% \mathrm{~A}$. The HPLC protocol consisted of $100 \%$ A for $10 \mathrm{~min}$, followed by a gradient of $0-100 \% \mathrm{~B}$ over $90 \mathrm{~min}$.

For fractionation of digested synthetic peptide (SLIGKV$\mathrm{OH}-$ or SFLLRN-NH$H_{2}$ ), solvents for HPLC were: A, 5\% acetonitrile containing $0.1 \%$ trifluoroacetic acid; $\mathrm{B}, 25 \%$ acetonitrile containing $0.1 \%$ trifluoroacetic acid. The column was equilibrated with $100 \%$ A. The HPLC protocol consisted of $100 \%$ A for $20 \mathrm{~min}$, a gradient of $0-20 \%$ B over $5 \mathrm{~min}$, followed by a gradient of $20-100 \% \mathrm{~B}$ over $60 \mathrm{~min}$.

Sample injection volume was $10 \mu \mathrm{l}$. Protein digests fractions were collected every $30 \mathrm{~s}$. Each fraction was lyophilized, and then dissolved in $20 \mu \mathrm{l}$ of $2: 3$ acetonitrile $/ 0.1 \%$ trifluoroacetic acid for analysis of matrix-assisted laser desorption/ionization time-of-flight mass spectrometry

\section{(MALDI-TOF MS).}

Analysis of Py4 in Py4-Modified Peptide Py4-modified synthetic peptides were separated and collected by HPLC. The collected fractions were lyophilized, and then dissolved in $100 \mu \mathrm{l}$ of water. After the solution was diluted with the same volume of conc. $\mathrm{HCl}$ (final $6 \mathrm{M} \mathrm{HCl}$ ), the mixture was heated at $110^{\circ} \mathrm{C}$ for $24 \mathrm{~h}$ under nitrogen. The reaction mixture was lyophilized, and then dissolved in $100 \mu \mathrm{l}$ of $30 \%$ acetonitrile containing $0.1 \%$ trifluoroacetic acid.

Py4 was analyzed by HPLC on a packed $\mathrm{C}_{18}$ column (TOSOH ODS $120 \mathrm{~T}, 4.6 \times 250 \mathrm{~mm}$ ). Flow rate was 1.0 $\mathrm{ml} / \mathrm{min}$ and column temperature was $40^{\circ} \mathrm{C}$. Fluorescence was monitored at Ex $310 \mathrm{~nm}$ and Em $390 \mathrm{~nm}$. The sample injection volume was $10 \mu \mathrm{l}$. Solvent for HPLC was $25 \%$ acetonitrile containing $0.1 \%$ trifluoroacetic acid and $8 \mathrm{~mm}$ 1-octaneslufonic acid. Py4 was eluted at $9.3 \mathrm{~min}$.

Mass Spectrometry All mass spectra were obtained in the reflectron mode using an AXIMA-CFR MALDI-TOF (Shimadzu/Kratos, Manchester, U.K.) equipped with a $337 \mathrm{~nm}$ pulsed nitrogen laser. External mass calibration was performed with a mixture of peptide standards (angiotensin II, $m / z$ 1046.54; insulin $\beta$ chain, $m / z$ 3495.65). The matrix, $\alpha$-cyano-4-hydroxycinnamic acid, was prepared at a concentration of $10 \mathrm{mg} / \mathrm{ml}$ in $2: 3$ acetonitrile $/ 0.1 \%$ trifluoroacetic acid. The sample $(1.0 \mu \mathrm{l})$ was spotted onto the sample plate, $1.0 \mu \mathrm{l}$ of matrix was added, and the spot was allowed to dry at room temperature. Peptide sequences were determined by the post-source decay (PSD) method.

\section{RESULTS}

Detection of Py4-Modified Peptide during Protease Digestion Although the polyamine modification of peptides during tryptic digestion was previously confirmed by mass spectrometry, ${ }^{3)}$ the modification was not fully investigated because polyamine modified peptides were hard to be distinguished by HPLC with a UV detector. Therefore, it was necessary to select a model alkylamine for high sensitivity detection of modified peptides by HPLC analysis. In the present study, Py4 (Fig. 1) was synthesized and used as a model alkylamine because of its resemblance to polyamine and its high fluorescence, which allows detection without any significant effect on sensitivity in MALDI-TOF MS analysis (data not shown). The detection limit of Py4 on the HPLC with fluorescence detection was about $0.5 \mathrm{pmol}(\mathrm{S} / \mathrm{N}=3)$.

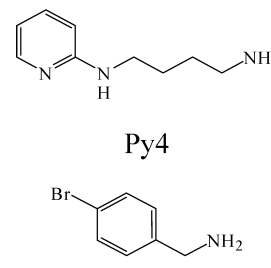

BrBA

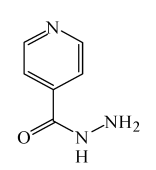

$\mathrm{INH}$

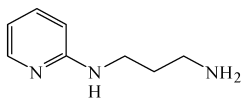

Py3

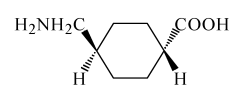

TA

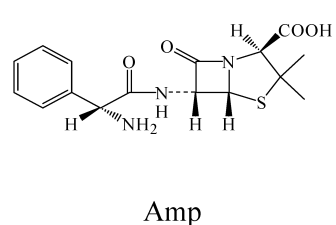

Fig. 1. Structure of Tested Alkylamines 
In order to confirm the modification of peptide with Py4, HB was used as a model protein, and was treated with trypsin in the presence of $50 \mathrm{~mm}$ Py4. The products were separated by HPLC and collected every $30 \mathrm{~s}$. On the chromatogram, digested peptides were eluted between 30 and $55 \mathrm{~min}$, while intact $\alpha$ and $\beta$ chains of HB were eluted at 68 and $72 \mathrm{~min}$, respectively, as shown in Figs. 2A and B. Although the exact mechanisms are unclear, trypsin digestion was slightly hindered by the added Py4. Some fluorescence peaks were detected on the chromatograms for samples treated with trypsin in the absence of Py4 (Fig. 2C), but nu-

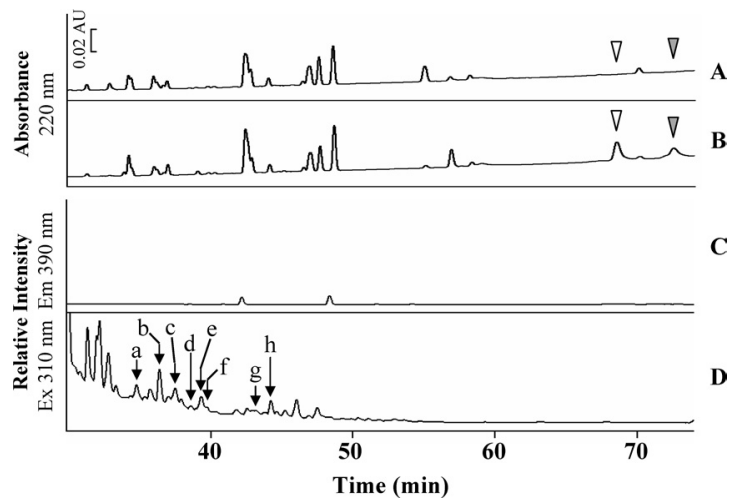

Fig. 2. HPLC Chromatograms of Tryptic Digestion Products of HB in the Presence or Absence of Py4

Tryptic digestion products of $\mathrm{HB}$ in the absence $(\mathrm{A}, \mathrm{C})$ or in the presence $(\mathrm{B}, \mathrm{D})$ of Py4 were analyzed by HPLC with UV absorbance (A,B) and fluorescence detection (C,D) on a packed C18 column (TOSOH ODS $120 \mathrm{~T}, 4.6 \times 250 \mathrm{~mm}$ ). UV absorption was monitored at $220 \mathrm{~nm}$. Fluorescence detection was monitored at Ex $310 \mathrm{~nm}$ and Em $390 \mathrm{~nm}$. Eluates were collected every $30 \mathrm{~s}$ for mass analysis. White and gray arrows (A,B) indicate the retention time of the $\alpha$ and $\beta$ chains of HB, respectively. Black arrow of $\mathrm{a}, \mathrm{b}, \mathrm{c}, \mathrm{d}, \mathrm{e}, \mathrm{f}, \mathrm{g}$ or $\mathrm{h}$ indicates the retention time of modified peptide of $\beta 19$ $29, \beta 95-103, \alpha 17-31, \beta 132-143, \alpha 91-99, \beta 8-18, \beta 65-81$ or $\beta 120-131$, respectively, identified by MS as shown in Table 1 . merous peaks were detected for those in the presence of Py4 (Fig. 2D).

When each fraction was analyzed by MALDI-TOF MS and PSD, it was found that eight peptides were modified with Py4 at the C-terminus, as shown by the arrows in Fig. 2D and Table 1. The PSD spectra of a modified peptide eluted at 37 min (c in Fig. 2D) is shown in Fig. 3. Based on the parent ion and the fragment ions, the sequence of the 1677 Da peptide was confirmed to be VGGHAAEYGAEALER-Py4 (17-31 of HB $\alpha$ chain), which corresponds to a portion of the HB sequence (Swiss-Prot Accession No. P01966 and P02070). The modified peptides were not always detected by MS (mass spectrometry) in every fluorescence peaks fraction in HPLC. Ionization of the modified peptide in MS may be repressed because of co-presence of easily-ionized non-mod-

Table 1. Detection of C-Terminal Py4-Modified Peptide by MALDI-TOF MS Analysis and PSD

\begin{tabular}{ccrr}
\hline \hline $\begin{array}{c}\text { Retention } \\
\text { time } \\
{[\mathrm{min}]}\end{array}$ & Fragment & Sequence & $\begin{array}{c}\text { Monoisotopic } \\
\mathrm{MH}^{+} \text {at } m / z \\
\text { (Calculated } \\
\text { monoisotopic mass) }\end{array}$ \\
\hline 34.5 & $\beta 19-29$ & VDEVGGEALGR-Py4 & $1248.6(1248.8)$ \\
36.0 & $\beta 95-103$ & LHVDPENFK-Py4 & $1245.5(1244.8)$ \\
37.0 & $\alpha 17-31$ & VGGHAAEYGAEALER-Py4 & $1676.4(1676.9)$ \\
38.5 & $\beta 132-143$ & VVAGVANALAHR-Py4 & $1324.5(1324.9)$ \\
39.0 & $\alpha 91-99$ & LRVDPVNFK-Py4 & $1234.3(1234.8)$ \\
39.5 & $\beta 8-18$ & AAVTAFWGKVK-Py4 & $1324.3(1324.9)$ \\
43.0 & $\beta 65-81$ & KVLDSFNGMKHLDDLK-Py4 & $2093.7(2094.2)$ \\
44.0 & $\beta 120-131$ & EFTPVLQADFQK-Py4 & $1569.9(1569.9)$
\end{tabular}

HB digestion with trypsin was performed in the presence of $50 \mathrm{~mm}$ Py4. Tryptic digestion products were separated and fractionated every $30 \mathrm{~s}$ by HPLC, and fractions including fluorescence peaks on HPLC chromatograms (Fig. 2D) were analyzed by MALDI-TOF MS and PSD.
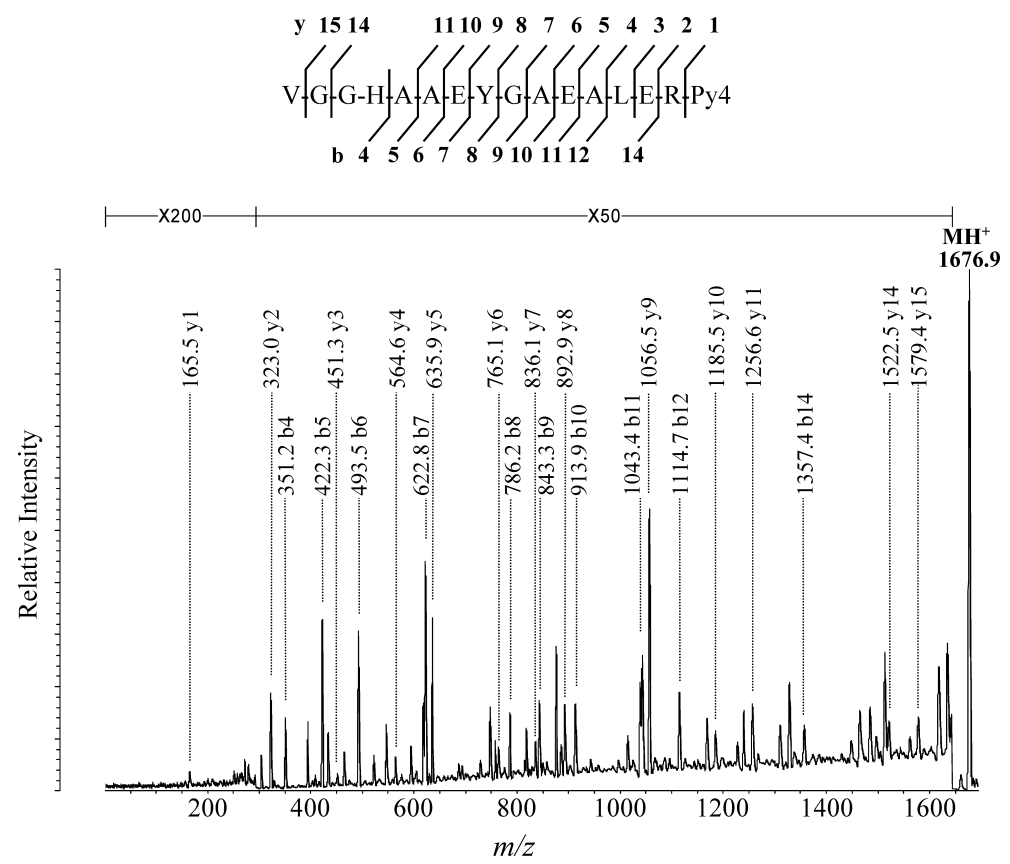

Fig. 3. PSD Spectrum of Protonated C-Terminus of Py4-Modified Peptide (1677 Da)

When the HB $\alpha$ chain Py4-modified peptide spanning residues 17 to 31 (VGGHAAEYGAEALER-Py4, 1677 Da) was used as a parent ion for PSD, sequential fragment b ions $(4-12,14)$ and y ions $(1-11,14,15)$ were observed. Calculated mass (Da) of b ions are 100.1 (b1), 157.2 (b2), 214.2 (b3), 351.4 (b4), 422.5 (b5), 493.5 (b6), 622.7 (b7), 785.8 (b8), 842.9 (b9), 914.0 (b10), 1043.0 (b11), 1114.1 (b12), 1227.3 (b13), 1356.4 (b14) and 1512.6 (b15). Calculated mass (Da) of y ions are 166.2 (y1), 322.4 (y2), 451.5 (y3),

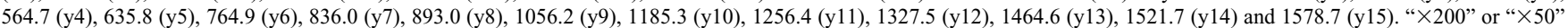
indicates the magnification of ion intensity. 
ified peptide.

Py4-modified peptides were also identified among the digestion products of $\mathrm{HB}$ and CytC (Swiss-Prot Accession No. P01966, P02070, P00004) treated with trypsin, chymotrypsin or elastase in the presence of $50 \mathrm{~mm}$ Py4, as shown in Table 2. All modified peptides were modified at the C-terminus (data not shown).

Dose and Time Dependency of Alkylamination The dependency of reaction time and dose for HB or Py4 was examined by monitoring the formation of Py4-modified peptides (17-31 of HB $\alpha$ chain), which could be detected from the early reaction stages. When degradation of HB was monitored by detecting the $\mathrm{HB} \alpha$ chain peak, the increase in formation of Py4-modified peptide was accompanied by the degradation of HB (Fig. 4). The formation of modified peptide was dependent on HB or Py4 concentration and was saturated at $25 \mathrm{~mm}$ Py4 (Fig. 5), thus suggesting that the modifi-

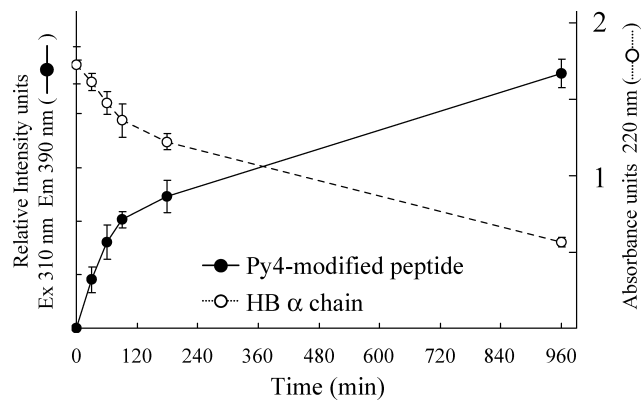

Fig. 4. Time Course of Py4 Modification Reaction in Trypsin Digestion and Degradation of $\mathrm{HB}$

Tryptic digestion products of HB in the presence of Py4 were analyzed by HPLC Relative fluorescence intensity of the peak area of Py4-modified peptide (17-31 of HB $\alpha$ chain, VGGHAAEYGAEALER-Py4) and absorbance unit of peak area of HB $\alpha$ chain are shown $(n=3)$. cation was enzymatic.

Alkylamination in Mixed Methanol-Water Solvent The effects of methanol on formation of Py4-modified peptide were examined. When HB was treated with trypsin in 17,34 or $50 \%$ methanol in the presence of Py4, the peak area of the modified peptide (17-31 of HB $\alpha$ chain) on the chromatogram was about $3.2 \pm 0.9,14.0 \pm 0.9$ or $18.6 \pm 1.1$ times greater than that of the control sample $(0 \%$ methanol), respectively $(n=3)$. These results suggest that methanol en-
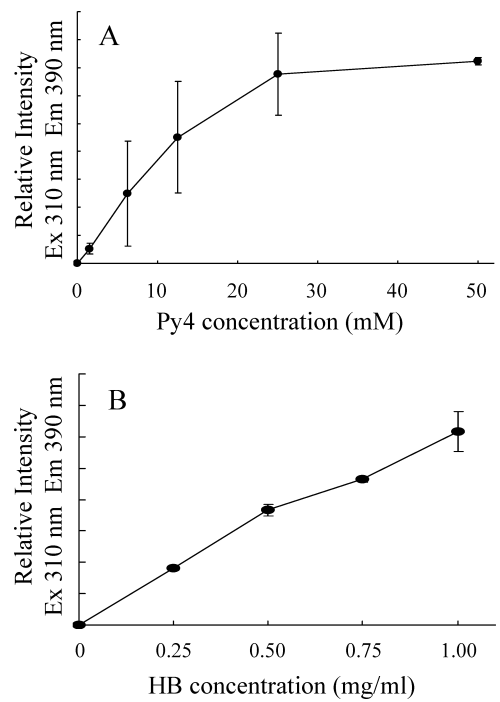

Fig. 5. Effects of $\mathrm{HB}$ or Py4 Concentration on Py4 Modification in Trypsin Digestion

Tryptic digestion products of HB in the presence of Py4 were analyzed by HPLC. Formation of Py4-modified peptide (17-31 of HB $\alpha$ chain, VGGHAAEYGAEALER Py4) in the presence of $1 \mathrm{mg} / \mathrm{ml} \mathrm{HB}$ (A) or $50 \mathrm{~mm}$ Py4 (B) was monitored in order to determine the effects Py4-concentration (A) and HB-concentration (B), respectively $(n=3)$.

Table 2. Detection of C-Terminal Py4-Modified Peptide by MALDI-TOF MS Analysis and PSD

\begin{tabular}{|c|c|c|c|c|}
\hline Protease & Protein & Fragment & Sequence & $\begin{array}{c}\text { Monoisotopic } \mathrm{MH}^{+} \text {at } \mathrm{m} / \mathrm{z} \\
\text { (Calculated monoisotopic mass) }\end{array}$ \\
\hline \multirow[t]{2}{*}{ Trypsin } & \multirow[t]{2}{*}{ CytC } & $39-53$ & KTGQAPGFTYTDANK-Py4 & $1618.2(1617.9)$ \\
\hline & & $40-53$ & TGQAPGFTYTDANK-Py4 & $1746.7(1746.0)$ \\
\hline \multirow[t]{12}{*}{ Chymotrypsin } & \multirow[t]{11}{*}{$\mathrm{HB}$} & $\alpha 1-24$ & VLSAADKGNVKAAWGKVGGHAAEY-Py4 & $2545.0(2545.4)$ \\
\hline & & $\alpha 3-14$ & SAADKGNVKAAW-Py4 & $1364.6(1364.8)$ \\
\hline & & $\alpha 15-24$ & GKVGGHAAEY-Py4 & $1135.6(1135.7)$ \\
\hline & & $\alpha 35-42$ & SFPTTKTY-Pу4 & $1091.6(1091.7)$ \\
\hline & & $\alpha 67-73$ & TKAVEHL-Py4 & $944.5(944.6)$ \\
\hline & & $\alpha 92-98$ & RVDPVNF-Py4 & $993.5(993.6)$ \\
\hline & & $\alpha 110-117$ & ASHLPSDF-Py4 & $1020.5(1020.6)$ \\
\hline & & $\beta 15-27$ & GKVKVDEVGGEAL-Py4 & $1448.0(1447.9)$ \\
\hline & & $\beta 32-36$ & VVYPW-Py4 & $810.4(810.5)$ \\
\hline & & $\beta 96-102$ & HVDPENF-Py4 & $1004.4(1004.6)$ \\
\hline & & $\beta 122-129$ & TPVLQADF-Py4 & $1037.8(1037.7)$ \\
\hline & CytC & $1-10$ & Ac-GDVEKGKKIF-Py4 & $1310.1(1309.9)$ \\
\hline \multirow[t]{8}{*}{ Elastase } & \multirow[t]{3}{*}{ HB } & $\alpha 35-48$ & SFPTTKTYFPHFDL-Py4 & $1847.9(1848.1)$ \\
\hline & & $\beta 31-47$ & LVVYPWTQRFFESFGDL-Py4 & $2251.1(2251.3)$ \\
\hline & & $\beta 126-137$ & QADFQKVVAGVA-Py4 & $1379.3(1379.9)$ \\
\hline & \multirow[t]{5}{*}{ CytC } & $4-15$ & EKGKKIFVQKCA-Py4 & $1525.9(1526.0)$ \\
\hline & & $7-15$ & KKIFVQKCA-Py4 & $1211.8(1211.8)$ \\
\hline & & $12-24$ & QKCAQCHTVEKGG-Py4 & $1534.8(1535.8)$ \\
\hline & & $35-41$ & LFGRKTG-Py4 & $925.3(925.6)$ \\
\hline & & $85-98$ & IKKKTEREDLIAYL-Py4 & $1867.2(1867.2)$ \\
\hline
\end{tabular}

HB or CytC digestion with trypsin, chymotrypsin or elastase was performed in the presence of 50 mm Py4. Proteolytic digests were separated and fractionated every $30 \mathrm{~s}$ by HPLC, and fractions including fluorescence peaks on HPLC chromatograms were analyzed by MALDI-TOF MS and PSD. 
hances the reactivity of alkylamine to the protein-acyl-enzyme intermediate.

Evaluation of Formation Rate of Py4-Modified Peptide in Protein Digestion In order to analyze the formation rate

Table 3. Detection of Alkylamine-Modified Peptide by MALDI-TOF MS Analysis and PSD

\begin{tabular}{|c|c|c|c|}
\hline Alkylamine & Fragment & Sequence & $\begin{array}{c}\text { Average } \mathrm{MH}^{+} \\
\text {at } \mathrm{m} / \mathrm{z} \\
\text { (Calculated average } \\
\text { mass) }\end{array}$ \\
\hline \multirow[t]{5}{*}{ Рy3 } & $\alpha 12-16$ & AAwGK-Py3 & $666.4(665.8)$ \\
\hline & $\alpha 17-31$ & VGGHAAEYGAEALER-Py3 & $1664.1(1663.8)$ \\
\hline & $\beta 76-81$ & HLDDLK-Py3 & $874.8(874.0)$ \\
\hline & $\beta 1-7$ & MLTAEEK-Py3 & $954.0(955.2)$ \\
\hline & $\beta 17-29$ & VKVDEVGGEALGR-Py3 & $1462.7(1462.7)$ \\
\hline \multirow[t]{5}{*}{ BrBA } & $\alpha 91-99$ & LRVDPVNFK-BrBA & $1256.7(1255.6)$ \\
\hline & $\alpha 17-31$ & VGGHAAEYGAEALER-BrBA & $1698.8(1697.7)$ \\
\hline & $\alpha 41-56$ & TYFPHFDLSHGSAQVK-BrBA & 2003.5 (2001.9) \\
\hline & $\beta 132-143$ & VVAGVANALAHR-BrBA & $1346.8(1345.7)$ \\
\hline & $\beta 30-39$ & LLVVYPWTQR-BrBA & $1443.9(1442.7)$ \\
\hline \multirow[t]{7}{*}{ INH } & $\alpha 8-16$ & GNVKAAWGK-INH & $1049.3(1050.2)$ \\
\hline & $\alpha 91-99$ & LRVDPVNFK-INH & $1207.1(1207.4)$ \\
\hline & $\alpha 128-139$ & FLANVSTVLTSK-INH & $1398.8(1399.6)$ \\
\hline & $\alpha 17-31$ & VGGHAAEYGAEALER-INH & $1649.1(1649.8)$ \\
\hline & $\alpha 1-16$ & VLSAADKGNVKAAWGK-INH & $1735.8(1735.0)$ \\
\hline & $\beta 82-94$ & GTFAALSELHCDK-INH & $1511.8(1511.7)$ \\
\hline & $\beta 66-81$ & VLDSFSNGMKHLDDLK-INH & $1939.4(1939.2)$ \\
\hline \multirow[t]{7}{*}{ TA } & $\alpha 1-7$ & VLSAADK-TA & $842.9(843.0)$ \\
\hline & $\alpha 93-99$ & VDPVNFK-TA & $958.0(958.1)$ \\
\hline & $\alpha 32-40$ & MFLSFPTTK-TA & $1212.4(1211.5)$ \\
\hline & $\alpha 17-31$ & VGGHAAEYGAEALER-TA & $1669.5(1669.8)$ \\
\hline & $\alpha 41-56$ & TYFPHFDLSHGSAQVK-TA & $1973.2(1974.2)$ \\
\hline & $\beta 17-29$ & VKVDEVGGEALGR-TA & $1467.9(1468.7)$ \\
\hline & $\beta 1-16$ & MLTAEEKAAVTAFWGK-TA & $1893.1(1893.3)$ \\
\hline \multirow[t]{2}{*}{ Amp } & $\alpha 17-31$ & VGGHAAEYGAEALER-Amp & $1862.5(1862.0)$ \\
\hline & $\alpha 69-92$ & AVEHLDDLPGALSELSDLHAHKLR-Amp & $2969.6(2969.4)$ \\
\hline
\end{tabular}

HB digestion with trypsin was performed in the presence of $50 \mathrm{~mm}$ of $\mathrm{Py} 3, \mathrm{BrBA}$, INH, TA or Amp. The proteolytic digests were separated and fractionated every $30 \mathrm{~s}$ by HPLC, and every fraction was analyzed by MALDI-TOF MS and PSD. of Py4-modified peptide, synthetic peptide (SLIGKV-OH or SFLLRN-NH ${ }_{2}$ ) was treated with trypsin in the presence of Py4. The products (SLIGK-OH, SLIGK-Py4, SFLLR-OH or SFLLR-Py4) were separated and collected by HPLC and identified by PSD. After hydrolysis of the collected SLIGKPy 4 or SFLLR-Py4 fraction with $6 \mathrm{M} \mathrm{HCl}$, the recovered Py 4 was analyzed by HPLC to calculate the amount of modified peptide, and the formation rate was calculated by dividing the amount of modified peptide by the initial amount of synthetic peptide used. The formation rates of SLIGK-Py4 and SFLLR-Py4 were $0.07 \pm 0.01 \%$ and $0.09 \pm 0.01 \%$, respectively $(n=3)$.

Modification with Various Alkylamines Peptide modification was examined with a range of alkylamines. HB was treated with trypsin in the presence of $50 \mathrm{~mm}$ of Py3, BrBA, INH, TA or Amp (Fig. 1) for $16 \mathrm{~h}$. In all cases, alkylaminemodified peptides were detected by MALDI-TOF MS analysis (Table 3) and identified by PSD. In case of Amp, HB was treated with trypsin in $25 \%$ methanol in order to increase the formation of the modified peptide. A PSD spectrum from a sample digested in the presence of Amp is shown in Fig. 6.

\section{DISCUSSION}

Our results clearly demonstrated that the amine modification occurring in the presence of protease and alkylamine is enzymatic, and that a variety of alkylamines, including Amp, are able to form alkylamide bonds at the C-terminus of serine protease-digested peptides. In addition to intestinal serine protease, other serine or cysteine proteases involved in protein degradation systems, such as plasmin ${ }^{4)}$ or calpain, ${ }^{5)}$ may also produce modified peptides in the presence of biogenic amines. Furthermore, lipases, serine hydrolases, catalyze the hydrolysis of esters by the same double-displacement mechanism via an acyl-enzyme intermediate, as observed with serine proteases. $\left.{ }^{6}\right)$ Therefore, the present results suggest that
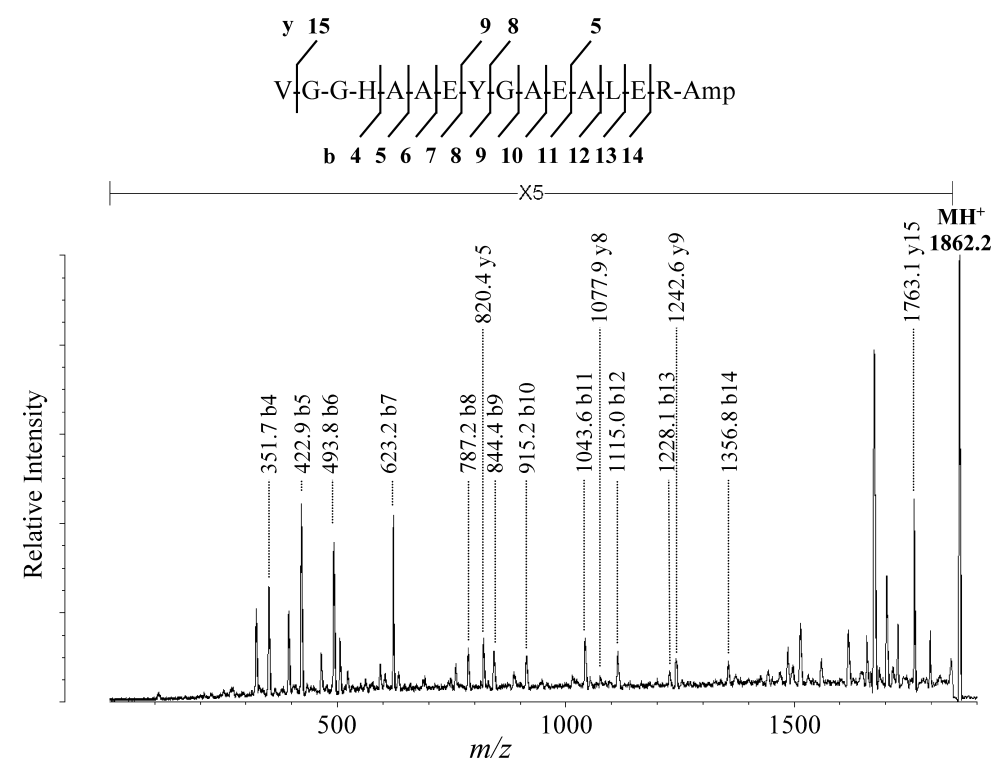

Fig. 6. PSD Spectrum of Protonated C-Terminus of Amp-Modified Peptide (1862 Da)

When the HB $\alpha$ chain Amp-modified peptide spanning residues 17 to 31 (VGGHAAEYGAEALER-Amp, 1862 Da) was used as a parent ion for PSD, sequential fragment b ions $(4-14)$ and y ions $(5,8,9,15)$ were observed. Calculated mass (Da) of b ions are 100.1 (b1), 157.2 (b2), 214.2 (b3), 351.4 (b4), 422.5 (b5), 493.5 (b6), 622.7 (b7), 785.8 (b8), 842.9 (b9), 914.0 (b10), 1043.1 (b11), 1114.1 (b12), 1227.3 (b13), 1356.4 (b14) and 1512.6 (b15). Calculated mass (Da) of y ions are 351.4 (y1), 507.6 (y2), 636.7 (y3), 749.9 (y4), 821.0 (y5), 950.1 (y6), 1021.2 (y7), 1078.2 (y8), 1241.4 (y9), 1370.5 (y10), $1441.6(\mathrm{y} 11), 1512.7$ (y12), 1649.8 (y13), 1706.8 (y14) and 1763.9 (y15). “ $\times 5$ ” indicates the magnification of ion intensity. 
these modifications might occur during the hydrolysis of amides or ester bonds in the presence of amines in a variety of biological systems.

The formation rate of modified products from synthetic peptides in the presence of $50 \mathrm{~mm}$ Py4 with trypsin was below $c a$. $0.1 \%$. The rate was not substantial in vitro, but might be significant for protein digestion in the gastrointestinal tract. As shown in Fig. 5A, the formation of modified peptides from $\mathrm{HB}$ in the presence of $1 \mathrm{~mm}$ Py 4 was one tenth that of $50 \mathrm{~mm}$ Py4, thus suggesting that the formation rate is significant even in the presence of $1 \mathrm{~mm}$ of alkylamine. Considering that the daily protein intake for an adult is about $60 \mathrm{~g}$, or about $0.5 \mathrm{~mol}$ of amino acid $(0.8 \mathrm{~g} / \mathrm{kg}$ body weight $){ }^{7}{ }^{7}$ the total modified peptide or amino acid formed in the gastrointestinal tract may reach the $\mu \mathrm{mol} / \mathrm{d}$ level. As polyamine concentrations in the intestine reach almost mu levels shortly after a meal, ${ }^{8)}$ polyamine modification of peptides would occur at significant levels every day. Therefore, the polyamine-modified peptides formed would have several novel effects on the body and such amine modification could be involved in the effects of certain foods on disease state.

Bulky alkylamines, such as Amp, were also able to react with acyl-enzyme intermediates during protein digestion. Therefore, drugs having primary amino groups that are administered at high doses may become a substrate for protease-mediated alkylamination. Drugs administered as enteric-coated preparations would be particularly expected to form modified peptides at high levels due to the higher drug concentrations in the intestine. Drug-modified peptides may thus be related to unknown and/or undesired pharmacological effects.

Acknowledgements The authors are grateful to Professor S. Matsufuji (Jikei University, Tokyo, Japan) for access to the AXIMA-CFR MALDI-TOF. The authors would also like to thank Ms. M. Wada, Ms. M. Yashiki, Mr. S. Miyatake, Mr. M. Kusakabe, Mr. K. Yamazaki, Mr. Y. Tezuka and Ms. I. Ishii for helpful discussions. This work was supported by a Grant-in-Aid for Scientific Research (C) (2) (No. 16590033) from the Japan Society for the Promotion of Science.

\section{REFERENCES}

1) Nemes Z., Petrovski G., Fesus L., Anal. Biochem., 342, 1-10 (2005).

2) Tobin J. B., Whitt S. A., Cassidy C. S., Frey P. A., Biochemistry, 34, 6919-6924 (1995).

3) Ito T., Sugita Y., Ikeguchi Y., Shirahata A., Biochem. Biophys. Res. Commun., 356, 159-162 (2007).

4) Castellino F. J., Ploplis V. A., Thromb. Haemostasis, 93, 647-654 (2005).

5) Ono Y., Kakinuma K., Torii F., Irie A., Nakagawa K., Labeit S., Abe K., Suzuki K., Sorimachi H., J. Biol. Chem., 279, 2761-2771 (2004).

6) Jaeger K. E., Dijkstra B. W., Reetz M. T., Annu. Rev. Microbiol., 53, 315-351 (1999).

7) Pellet P. L., Am. J. Clin. Nutr., 51, $723-737$ (1990).

8) Seidel E. R., Scemama J. L., J. Nutr. Biochem., 8, 104-111 (1997). 